\title{
Aspectos fisiológicos, anatômicos e ultra-estruturais do rizoma de Costus arabicus L. (Costaceae) sob condições de déficit hídrico ${ }^{1}$
}

\author{
Vanessa Pires da Costa $^{2}$, Adriana Hissae Hayashi ${ }^{3}$, Maria Angela Machado de Carvalho \\ e Emerson Alves da Silva ${ }^{2,4}$
}

Recebido: 27.10.2011; aceito: 13.03.2012

\begin{abstract}
Physiological, anatomical and ultrastructural aspects of the rhizome of Costus arabicus L. (Costaceae) under water deficit conditions). Costus arabicus L. is an herbaceous species, native to the forest that accumulates starch in the rhizome as the main reserve carbohydrate. Water stress is one the most important environmental factor that regulates plant growth and development, leading to changes in physiological, biochemical and anatomical traits. The aim of this study was to evaluate the effect of water deficit on the anatomy, carbohydrate concentration and ultrastructure of starch grains of the rhizome of Costus arabicus L. through the following water regimes: plants irrigated daily and every seven (7d) and 15 days (15d). Anatomical and ultrastructural traits of the rhizome, relative water content in leaves (RWC), leaf water potential $(\Psi \mathrm{w})$, osmotic potential of the rhizome ( $\Psi_{\mathrm{o}}$ ), total soluble sugars (TSS), reducing sugars (RS) and starch of the rhizome were evaluated. We observed significant reductions in $\Psi_{\mathrm{w}}$ and $\Psi \mathrm{s}$ in $15 \mathrm{~d}$ plants, but with small variations in the RWC. The anatomical analysis showed that the rhizome is covered by epidermis or stratified cork and there is a delimitation between the cortical and vascular regions. We detected the presence of numerous starch grains and idioblasts with phenolic contents in the parenchyma of the two regions. Changes in the anatomy of the rhizomes were only observed in plants irrigated every 15 days, in which cells of covering tissue and the outer cortical layers became more flattened and sinuous walls; however, no ultrastructural differences were observed on the starch grains. The water deficit imposed was sufficient to generate physiological, biochemical and anatomical changes in plants of $C$. arabicus L. Such alterations suggest the occurence of an avoidance mechanism and that anatomical changes were dependent of the intensity and duration of water deficit.
\end{abstract}

Key words: drought, starch, water stress

RESUMO - (Aspectos fisiológicos, anatômicos e ultra-estruturais do rizoma de Costus arabicus L. (Costaceae) sob condições de déficit hídrico). Costus arabicus L. é uma espécie herbácea, nativa de mata, que acumula em seu rizoma amido como principal carboidrato de reserva. A seca é um dos fatores ambientais que pode regular o crescimento e o desenvolvimento das plantas, levando a alterações nas características fisiológicas, bioquímicas e anatômicas. Este trabalho objetivou avaliar a influência do déficit hídrico na anatomia, no conteúdo de carboidratos e na ultra-estrutura dos grãos de amido do rizoma de Costus arabicus L. submetidos aos ciclos de rega diário (Controle) e a cada sete (7d) e 15 dias (15d). Foram avaliados aspectos anatômicos e ultra-estruturais do rizoma, conteúdo relativo de água nas folhas (CRA), potencial hídrico foliar ( $\Psi w)$, potencial osmótico do rizoma ( $\Psi$ s), açúcares solúveis totais (AST) e redutores (AR) e amido do rizoma. Observaram-se reduções significativas do $\Psi_{\mathrm{w}}$ e do $\Psi_{\mathrm{s}}$ nas plantas $15 \mathrm{~d}$, porém com pequenas variações no CRA. Análises anatômicas mostraram que o rizoma é revestido pela epiderme ou súber estratificado e apresenta delimitação entre as regiões cortical e vascular que possuem numerosos grãos de amido e idioblastos com conteúdo fenólico. Alterações na anatomia dos rizomas foram observadas somente nas plantas irrigadas a cada 15 dias, em que as células do tecido de revestimento e das camadas corticais mais externas tornaram-se mais achatadas e com paredes sinuosas, porém, sem diferenças ultra-estruturais dos grãos de amido. $\mathrm{O}$ déficit hídrico imposto foi suficiente para gerar mudanças fisiológicas, bioquímicas e anatômicas nas plantas de Costus arabicus L. Essas alterações sugerem a ocorrência de um mecanismo de evitação à seca e demonstram que as alterações anatômicas foram dependentes da intensidade e duração do déficit hídrico.

Palavras-chave: amido, estresse hídrico, seca

\section{Introdução}

O estresse hídrico por falta de água é um dos fatores ambientais mais importantes que podem regular o crescimento e o desenvolvimento das plantas, por meio de alterações fisiológicas e bioquímicas (Jones \& Corlett 1992, Zobayed et al. 2007). O déficit hídrico decorrente da seca se estabelece quando a absorção de

1. Parte da Dissertação de Mestrado da primeira Autora pelo PPG Fisiologia e Bioquímica de Plantas, ESALQ/USP, Piracicaba, SP, Brasil

2. Instituto de Botânica, Núcleo de Pesquisa em Fisiologia e Bioquímica, Caixa Postal 68041, 04045-972 São Paulo, SP, Brasil

3. Instituto de Botânica, Núcleo de Pesquisa em Anatomia, Caixa Postal 68041, 04045-972 São Paulo, SP, Brasil

4. Autor para correspondência: easilva@ibot.sp.gov.br 
água pelo sistema radicular não atende às demandas da planta (Fan et al. 2006) que envolvem principalmente dois processos essenciais ao crescimento vegetal: a fotossíntese e a transpiração dos órgãos aéreos. A comunicação do déficit hídrico entre o sistema radicular e a parte aérea é feita por vários meios, dentre os quais pela redução no fluxo ascendente de água, que gera uma resposta integrada da planta, permitindo sua sobrevivência até que a disponibilidade de água aumente (Davies \& Zhang 1991).

Desse modo, a sobrevivência das plantas sob tais condições estressantes depende em grande extensão da habilidade que as mesmas têm de "perceber" o estímulo, gerar e transmitir o sinal e iniciar várias alterações fisiológicas e bioquímicas (Bohnert \& Jansen 1996, Shinozaki \& Yamaguchi-Shinozaki 1997). O acúmulo de carboidratos em plantas contribui para sua aclimatação e/ou adaptação ao déficit hídrico (Pelleschi et al. 1997, Chaves et al. 2002). Esses compostos atuam como elementos-chave que podem ser armazenados tanto na forma de polissacarídeos com baixa atividade osmótica como o amido, quanto na forma de açúcares altamente solúveis e higroscópicos como a sacarose e as hexoses (Buckeridge et al. 2000, Whittaker et al. 2007).

Existem vários trabalhos sobre os efeitos do déficit hídrico na fisiologia de órgãos aéreos e subterrâneos em plantas. No entanto, a maioria deles utiliza como modelo espécies de interesse agronômico, tais como milho (Sharp \& Lenoble 2002, Sharp et al. 2004, Fan \& Neumann 2004), trigo (Asseng et al. 1998, Morillon \& Lassalles 2002, Piro et al. 2003), grão-de-bico (Basu et al. 2007), mandioca (Santisopasri et al. 2001) e batata (Geigenberger et al. 1997). Especificamente no caso da batata (Solanum tuberosum L.), que acumula amido como principal carboidrato de reserva em seus órgãos subterrâneos (tubérculos) e também uma das mais estudadas sob condições de estresse hídrico, os trabalhos realizados demonstram que a disponibilidade hídrica regula as taxas de síntese de amido e crescimento dos tubérculos (Oparka $\&$ Wright 1988a, b) e que tanto a síntese como a degradação desse carboidrato são alteradas sob condições de déficit hídrico, com respostas, em geral, associadas ao aumento nos níveis de açúcares solúveis e inibição da síntese de amido (Geigenberger et al. 1997). De acordo com esses autores, a direção da via metabólica para síntese de sacarose ou amido representam uma estratégia importante sob condições de déficit hídrico, visto que influenciam a regulação do potencial osmótico interno, das relações hídricas e, por extensão, do crescimento da planta.

Com efeito, foi observado recentemente que a formação e distribuição do tamanho dos grãos de amido de trigo, além de serem influenciadas pelo genótipo e pelo desenvolvimento da planta, também são determinadas por condições ambientais (Zhang et al. 2010). Esses autores verificaram que o tamanho dos grãos de amido de trigo com alto teor de amilose foram menos afetados pelo déficit hídrico do que os grãos com baixo teor de amilose.

Costus arabicus L. (Costaceae) é uma espécie herbácea, nativa de mata, conhecida popularmente como costus, canela-de-ema, cana-do-brejo, cana-de-macaco e gengibre-espiral (Lorenzi \& Souza 1999) e comumente utilizada como planta ornamental (Castro 1995) e na medicina popular (Oliveira et al. 2008). O rizoma acumula amido como principal carboidrato de reserva (Santos 2009), que perfaz cerca de $40 \%$ da massa seca desse órgão.

Estudos anatômicos e ultra-estruturais com espécies de monocotiledôneas portadoras de órgãos subterrâneos e relacionados com deficiência hídrica no solo são escassos, e a presença de rizomas em C. arabicus faz dessa espécie um excelente modelo para estudos nesse tema.

Assim, este trabalho tem como hipótese que o acúmulo, o tamanho e forma dos grãos de amido nos órgãos de reserva de $C$. arabicus são afetados pelo déficit hídrico.

Esta hipótese foi testada utilizando uma abordagem combinada de parâmetros ecofisiológicos, bioquímicos e anatômicos, visando ao entendimento dos processos de regulação do acúmulo e utilização de carboidratos para manutenção do status hídrico, durante o crescimento e o desenvolvimento das plantas sob condições de déficit hídrico.

O objetivo deste trabalho foi avaliar a influência do déficit hídrico na concentração de carboidratos, na anatomia e na ultra-estrutura dos grãos de amido do rizoma de Costus arabicus L.

\section{Material e métodos}

Material botânico e condições de cultivo - Plantas de Costus arabicus L. foram obtidas por propagação vegetativa a partir dos rizomas de plantas provenientes do Núcleo de Pesquisa em Fisiologia e Bioquímica do Instituto de Botânica. O material botânico foi coletado em canteiro experimental $\left(23^{\circ} 38^{\prime} \mathrm{S}\right.$ e $\left.46^{\circ} 37^{\prime} \mathrm{W}\right)$, herborizado e identificado, sendo a exsicata incorporada ao Herbário SP sob o número 420025. 
Os rizomas das plantas matrizes foram fragmentados em segmentos de $5 \mathrm{~cm}$ cada e plantados em vasos individuais de $20 \mathrm{~L}$, contendo substrato comercial Plantmax Café ${ }^{\circledR}$ (DDLAgroindústria Ltda.). As plantas foram cultivadas em casa de vegetação e irrigadas diariamente com água de torneira e semanalmente com solução nutritiva de Clark (Clark 1975).

A imposição do déficit hídrico foi realizada a partir do $6^{\circ}$ mês de cultivo quando as plantas apresentavam em média 6 hastes, 90 folhas e área foliar total de $0,2 \mathrm{~m}^{2}$. O experimento foi realizado entre os meses de janeiro e março de 2009, que compreende o período quente e úmido (verão). As plantas foram submetidas aos seguintes tratamentos: plantas irrigadas diariamente (controle), irrigadas a cada sete (7d) e a cada 15 dias (15d). As análises das relações hídricas e a coleta de amostras para a quantificação, de carboidratos e para os estudos de anatomia e ultra-estrutura dos grãos de amido foi realizada aos 75 dias após a imposição dos regimes de rega. $\mathrm{O}$ delineamento experimental do estudo anatômico e ultra-estrutural do rizoma foi inteiramente casualizado com três repetições (plantas) por tratamento, sendo as amostras de rizoma coletadas a $5 \mathrm{~cm}$ de distância do fragmento do rizoma que deu origem à nova planta. Para as análises das relações hídricas e da concentração dos carboidratos, o experimento foi disposto em delineamento inteiramente casualizado com quatro repetições (plantas) por tratamento.

Relações hídricas - Para quantificar a intensidade do déficit hídrico imposto às plantas nos diferentes tratamentos, foram realizadas medidas do potencial da água $\left(\Psi_{\mathrm{w}}\right)$ da terceira folha totalmente expandida a partir do ápice das plantas. As medidas de $\Psi_{\mathrm{w}}$ foram realizadas às 6 horas, utilizando-se uma câmara de pressão tipo Scholander, Modelo 1000 (PMS Instrument Co., Albany, Oregon, EUA). Para obtenção da osmolalidade, o suco celular dos rizomas foi coletado, armazenado em microtubos e mantido a $-20{ }^{\circ} \mathrm{C}$ até o momento da realização das medidas, utilizando-se um osmômetro de pressão de vapor modelo 5520 VAPRO (Wescor, Logan, Utah, EUA). Os valores obtidos em mmol kg-1 foram convertidos em potencial osmótico ( $\Psi s)$, por meio da equação de Van't Hoff em que $\Psi \mathrm{s}=-\mathrm{C} \times 2,58 \times 10^{-3}$, na qual $\mathrm{C}$ é o valor de osmolalidade obtido em $10 \mu \mathrm{L}$ de suco celular em cada medida.

Para medir o conteúdo relativo de água (CRA), as mesmas folhas utilizadas para medidas de $\Psi_{\mathrm{W}}$ foram imediatamente pesadas para a obtenção da massa fresca da folha (MFf). Em seguida, essas folhas foram submersas por 24 horas em Becker contendo água destilada e pesadas novamente para obtenção da massa fresca túrgida da folha (MTf). Posteriormente, as folhas foram colocadas em uma estufa a $60^{\circ} \mathrm{C}$ por 72 horas para a obtenção da massa seca da folha (MSf). O CRA foi calculado conforme descrito por Weatherley (1950) por meio da fórmula: CRA $(\%)=($ MFf-MSf/MTf-MSf $) \times 100$

Teor de carboidratos - A extração de carboidratos solúveis foi realizada segundo Carvalho et al. (1998) com modificações. Para a quantificação dos carboidratos solúveis, amostras de rizomas foram coletadas e imediatamente congeladas em nitrogênio líquido e, posteriormente, liofilizadas e pulverizadas em moinho de bola. Amostras do material $(500 \mathrm{mg}$ ) foram submetidas à extração em $10 \mathrm{~mL}$ de etanol $80 \% \mathrm{e}$ mantidas em banho-maria a $80{ }^{\circ} \mathrm{C}$ por 15 minutos, sendo então centrifugadas a $700 \mathrm{~g}$ por 15 minutos. Os resíduos foram submetidos a mais dois ciclos de extração em etanol $80 \%$ a $80{ }^{\circ} \mathrm{C}$ por 15 minutos, e novamente centrifugados, sendo os sobrenadantes das três extrações etanólicas reunidos. Os resíduos finais foram submetidos a duas extrações aquosas de $10 \mathrm{~mL}$ cada a $60^{\circ} \mathrm{C}$ por 30 minutos e filtrados à vácuo em tecido de algodão. Os sobrenadantes etanólicos e aquosos foram reunidos e concentrados em rotoevaporador a $40^{\circ} \mathrm{C}$. O resíduo restante após filtragem foi mantido a $-20^{\circ} \mathrm{C}$ para posterior dosagem do amido. A análise quantitativa dos açúcares solúveis totais (AST) dos extratos de rizoma foi realizada pelo método do fenol sulfúrico (Dubois et al. 1956) e a de açúcares redutores (AR) foi realizada de acordo com o método de Somogyi (1945). Os resíduos das extrações de carboidratos solúveis foram liofilizados, macerados e submetidos à quantificação de amido pelo método enzimático (Amaral et al. 2007).

Microscopia de luz (ML) e eletrônica de varredura (MEV) - Amostras do rizoma de três indivíduos de cada tratamento foram fixadas em solução de Karnovsky (Karnovsky 1965), desidratadas em série etílica, infiltradas e incluídas em resina plástica hidroxi-etil-metacrilato. Os blocos foram seccionados transversalmente em micrótomo rotativo (7-9 $\mu \mathrm{m}$ de espessura) e as secções foram coradas com azul de toluidina (Sakai 1973) em tampão fosfato e citrato (McIlvaine 1921) pH 4,5, para montagem de lâminas histológicas permanentes em resina sintética. 
Secções obtidas no micrótomo rotativo também foram submetidas ao lugol (Berlyn \& Miksche 1976) para evidenciar a presença de amido e ao Sudan IV (Jensen 1962) para a localização das substâncias lipofílicas. A observação dos grãos de amido também foi realizada sob luz polarizada. Para as amostras fixadas em sulfato ferroso em formalina (Johansen 1940), foram feitos cortes à mão-livre para a localização in situ dos compostos fenólicos totais. A captura de imagens digitais dos materiais preparados em lâminas foi realizada em microscópio Leica DM LB equipado com câmera de vídeo Leica DC 300F. As escalas micrométricas foram obtidas nas mesmas condições ópticas utilizadas.

Para as análises ultra-estruturais, amostras do rizoma de três indivíduos de cada tratamento foram fixadas em solução de Karnovsky (Karnovsky 1965), desidratadas em série etílica, secas pelo método do ponto crítico de $\mathrm{CO}_{2}$ (Horridge \& Tamm 1969), montadas sobre suportes de alumínio e metalizadas com ouro coloidal por 210 segundos. As observações e as eletromicrografias foram feitas ao microscópio eletrônico de varredura LEO modelo VP 435, operado a $20 \mathrm{kV}$, com as escalas diretamente impressas nas mesmas.

\section{Resultados}

Relações hídricas e teor de carboidratos - O déficit hídrico imposto às plantas de Costus arabicus L. proporcionou decréscimos significativos do potencial hídrico foliar $\left(\Psi_{\mathrm{w}}\right)$, principalmente das plantas irrigadas a cada 15 dias (15d), e reduções significativas no potencial osmótico da seiva do rizoma ( $\Psi \mathrm{s})$ em relação ao controle, porém, sem alterações significativas no conteúdo relativo de água (CRA) (tabela 1).

Com relação ao teor de açúcares solúveis totais (AST) e redutores (AR), houve diminuição significativa desses açúcares nas plantas submetidas ao déficit hídrico, ao passo que o teor de amido das plantas manteve-se igual ao do tratamento controle (tabela 1).

Aspectos anatômicos e ultra-estruturais dos rizomas das plantas sob rega diária - O sistema subterrâneo de C. arabicus (figura 1.1) é constituído por rizomas com crescimento horizontal, que apresentam nós e entrenós marcantes, gemas protegidas por catafilos e raízes adventícias originadas na região dos nós (figura 1.2). Em secção transversal, o rizoma apresenta a seguinte estrutura: epiderme ou súber estratificado, córtex e cilindro vascular (figura 2.1).

A epiderme é uniestratificada, constituída por células pequenas de formato retangular e paredes finas, e apresenta estômatos (figura 2.1). À medida que ocorre o crescimento em diâmetro do rizoma, o revestimento é substituído pelo súber estratificado (figuras 2.2-2.3).

O córtex é amplo e formado por células parenquimáticas de contorno arredondado e de diferentes tamanhos (figura 2.1). Apresenta idioblastos fenólicos de coloração amarelada in vivo e de aspecto denso ou granuloso, evidenciados pela coloração

Tabela 1. Potencial hídrico foliar $(\Psi \mathrm{w})$, potencial osmótico da seiva do rizoma ( $\Psi \mathrm{s})$, conteúdo relativo de água (CRA), açúcar solúvel total (AST), açúcar redutor (AR) e amido no rizoma de plantas de Costus arabicus L. irrigadas diariamente (controle), a cada sete (7d) e a cada 15 dias (15d), obtidos 75 dias após o início do experimento. Os valores representam a média $(\mathrm{n}=5)$. Letras comparam cada parâmetro nos diferentes tratamentos. Valores seguidos por letras diferentes indicam diferenças estatísticas entre os tratamentos (Tukey, $p \leq 0,05$ ).

Table 1. Leaf water potential $\left(\Psi_{\mathrm{w}}\right)$, osmotic potential of the rhizome sap ( $\left.\Psi_{\mathrm{s}}\right)$, relative water content (CRA), total soluble sugars (AST), reducing sugars (AR) and starch in the rhizome of plants of Costus arabicus L. daily irrigated (control), every seven ( $7 \mathrm{~d})$ and 15 days $(15 \mathrm{~d})$, obtained 75 days after the beginning of the experiment. Values represent the average $(\mathrm{n}=5)$. Values followed by different letters indicate statistical differences among treatments (Tukey, $p \leq 0.05$ ).

\begin{tabular}{lccccccc}
\hline \multirow{2}{*}{ Tratamentos } & \multicolumn{3}{c}{ Relações Hídricas } & \multicolumn{3}{c}{ Carboidratos } \\
\cline { 2 - 8 } & $\Psi_{\mathrm{w}}$ & CRA & $\Psi \mathrm{s}$ & & AST & AR & Amido \\
\cline { 2 - 8 } & $\mathrm{MPa}$ & $\%$ & $\mathrm{MPa}$ & \multicolumn{3}{c}{ mg g MS $^{-1}$} \\
\hline Controle & $-0,20 \mathrm{~b}$ & $97,38 \mathrm{a}$ & $-0,28 \mathrm{~b}$ & & $104,88 \mathrm{a}$ & $19,40 \mathrm{a}$ & $349,89 \mathrm{a}$ \\
$7 \mathrm{~d}$ & $-0,50 \mathrm{~b}$ & $95,93 \mathrm{a}$ & $-0,44 \mathrm{a}$ & & $72,14 \mathrm{~b}$ & $6,42 \mathrm{~b}$ & $415,94 \mathrm{a}$ \\
$15 \mathrm{~d}$ & $-1,28 \mathrm{a}$ & $77,30 \mathrm{a}$ & $-0,47 \mathrm{a}$ & & $76,88 \mathrm{~b}$ & $6,93 \mathrm{~b}$ & $408,15 \mathrm{a}$ \\
\hline
\end{tabular}


marrom a preto em material fixado em sulfato ferroso em formalina (figura 2.2). Apresenta também acúmulo de grãos de amido (figuras 2.3-2.6), exceto nas camadas subepidérmicas (figuras 2.3-2.4), e cristais em algumas células parenquimáticas. Os grãos de amido apresentam diferentes tamanhos e formas alongadas (bastonetes), arredondadas, ovais ou poligonais (figuras 2.4-2.5). Os traços foliares, envoltos por 1-2 camadas de bainha

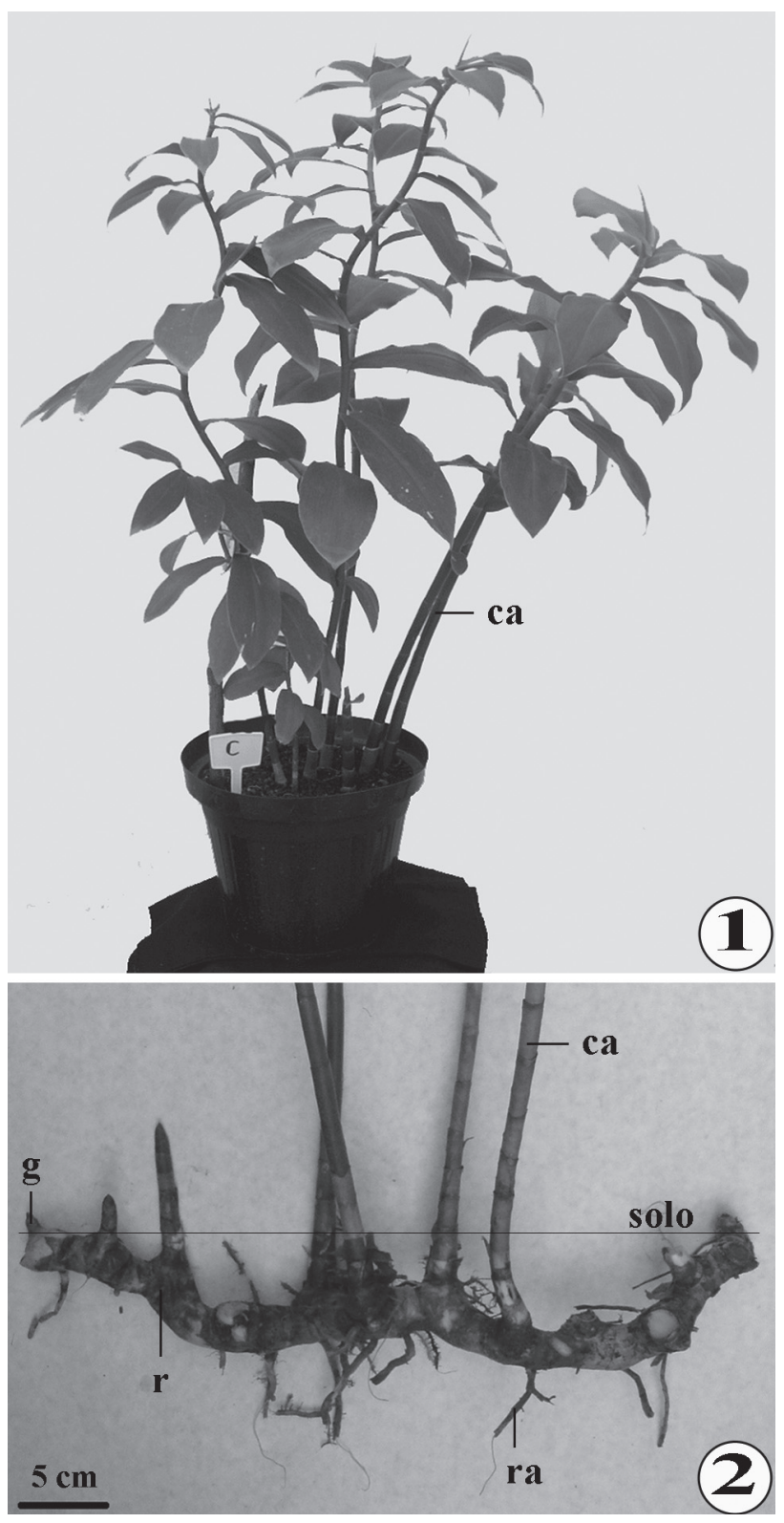

Figura 1. Planta de Costus arabicus L. 1. Aspecto geral da parte aérea. 2. Rizoma com crescimento horizontal, nós e entrenós. ca: caule aéreo; g: gema; r: rizoma; ra: raiz adventícia.

Figure 1. Plant of Costus arabicus L. 1. General aspect of aerial portion. 2. Rhizome showing horizontal growth with nodes and internodes. ca: aerial stem; $\mathrm{g}$ : bud; $\mathrm{r}$ : rhizome; ra : adventitious root. esclerenquimática, encontram-se distribuídos por todo o córtex (figuras 2.1-2.3) e também apresentam idioblastos com conteúdo fenólico. A endoderme, constituída por células arredondadas e menores, cujas paredes apresentam estrias de Caspary, delimita nitidamente as regiões cortical e vascular.

O cilindro vascular é atactostélico, delimitado pelo periciclo que apresenta 1-2 camadas de células retangulares de paredes finas que dão origem aos feixes vasculares do tipo colateral (figuras 2.1-2.2). Esses feixes podem apresentar idioblastos fenólicos e encontram-se envoltos por 1-2 camadas de bainha esclerenquimática (figuras 2.1-2.3), sendo que, em algumas das células da bainha, grãos de amido podem ser visualizados. No cilindro vascular, verificou-se, também, o acúmulo de grãos de amido nas células parenquimáticas e idioblastos com conteúdo fenólico. O teste com Sudan IV foi negativo para a presença de substâncias lipofílicas.

Aspectos anatômicos e ultra-estruturais dos rizomas das plantas sob déficit hídrico - Os rizomas das plantas irrigadas a cada sete dias (figura 3) apresentaram características anatômicas semelhantes às das plantas controle (figura 2). No entanto, nos rizomas das plantas irrigadas a cada 15 dias (figura 4), as células epidérmicas ou do súber estratificado e das camadas corticais mais externas tornaram-se mais achatadas e apresentaram paredes sinuosas, com tendência ao colapso das células. A progressão dessa sinuosidade da parede também pôde ser observada nas demais células em direção ao interior do órgão, mas de forma menos acentuada.

As células parenquimáticas do córtex das plantas irrigadas a cada sete e 15 dias também apresentaram inúmeros grãos de amido com diferentes tamanhos e formatos (bastonetes, arredondadas, ovais ou poligonais) (figuras 3.3-3.4, 4.3-4.4), como observado nas plantas irrigadas diariamente (figuras 2.4-2.5). A presença de idioblastos providos de conteúdo de coloração amarelada in vivo e de aspecto denso ou granuloso também foi verificada nas plantas irrigadas a cada sete e 15 dias (figuras 3.1, 4.1), inclusive nos feixes vasculares. Observaram-se traços foliares envoltos por 1-3 camadas de bainha esclerenquimática (figuras 3.1, 4.1) distribuídos por todo o córtex. Cristais foram visualizados em algumas células parenquimáticas.

\section{Discussão}

Relações hídricas e teor de carboidratos - Tanto o potencial hídrico das folhas $\left(\Psi_{\mathrm{W}}\right)$ quanto o potencial 

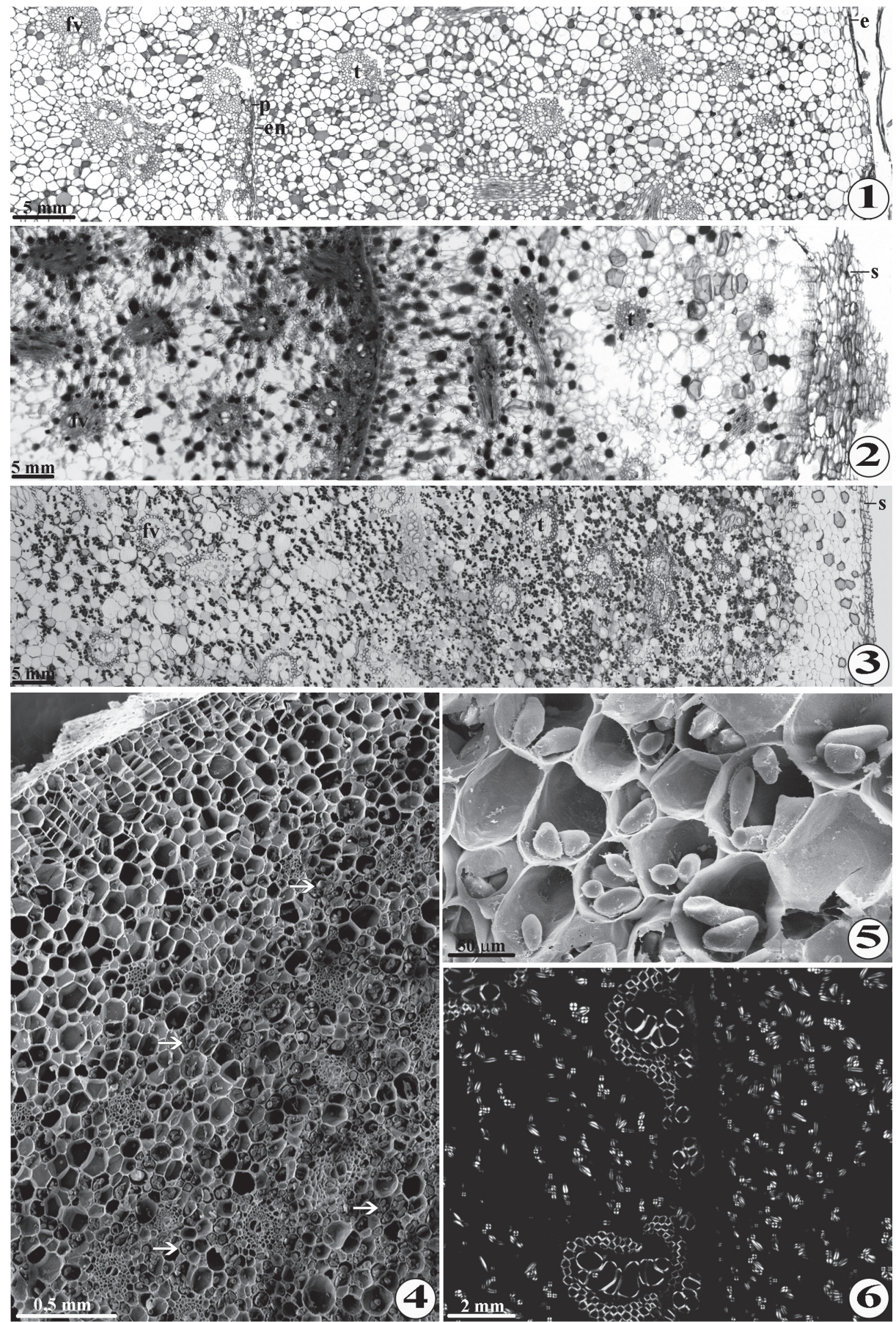

Figura 2. Secções transversais em microscopia de luz (1-3 e 6) e em microscopia eletrônica de varredura (4 e 5) do rizoma de plantas de Costus arabicus L. irrigadas diariamente (controle). 1. Secção corada com azul de toluidina mostrando a estrutura anatômica do rizoma. 2. Idioblastos com conteúdo fenólico no córtex e cilindro vascular do material fixado em sulfato ferroso em formalina. 3. Grãos de amido do córtex e do cilindro vascular corados com lugol. Observe a ausência de grãos de amido nas camadas subepidérmicas. 4. Aspecto geral do rizoma, mostrando os grãos de amido (setas). 5. Detalhe dos grãos de amido. 6. Grãos de amido sob luz polarizada. e: epiderme; en: endoderme; fv: feixe vascular; p: periciclo; s: súber; t: traço foliar.

Figure 2. Light microscopy (1-3 and 6) and scanning electron microscopy (4 and 5) of transversal sections of rhizomes of plants of Costus arabicus L. daily irrigated (control). 1. Section stained with toluidine blue, showing the anatomical structure of the rhizome. 2. Idioblasts containing phenols in the cortex and vascular cylinder from samples fixed in formalin ferrous sulfate. 3 . Starch grains in the cortex and vascular cylinder stained with lugol. Note the absence of starch grains in the subepidermal layers. 4. General aspect of the rhizome showing starch grains (arrows). 5. Detail of starch grains. 6. Starch grains under polarized light. e: epidermis; en: endodermis; fv: vascular bundle; p: pericycle; s: suber; t: leaf trace. 
osmótico da seiva do rizoma ( $\left.\Psi_{\mathrm{s}}\right)$ das plantas de Costus arabicus foram reduzidos em resposta aos tratamentos (irrigação a cada sete e 15 dias), embora o conteúdo relativo de água (CRA) das folhas tenha sido estatisticamente igual ao das plantas controle (irrigação diária). Segundo Turner (1986) e Bray (1993), a diminuição do potencial osmótico através do aumento real de solutos intracelulares (ajuste osmótico) é um mecanismo importante desenvolvido pelas plantas submetidas às condições de seca.

Em Costus arabicus o que se observou foi uma diminuição dos AST e AR em plantas sob deficiência hídrica, o que pode ser um indicativo de que esses carboidratos não estejam associados à osmorregulação intracelular, e sim, possivelmente, ao consumo desses compostos para respiração de manutenção do rizoma e sobrevivência da planta. Melo et al. (2007) observaram comportamento semelhante desses carboidratos em raízes de Paspalum paniculatum L. e Setaria anceps Stapf ex Broun \& R.E. Massey sob déficit hídrico. Porém, tais resultados diferem daqueles obtidos por Pastorini et al. (2003) que observaram aumento no teor de AST em tubérculos de Solanum tuberosum L., espécie que também acumula amido, cultivadas sob estresse hídrico no período da primavera, sugerindo o envolvimento desses carboidratos na osmorregulação das plantas para manutenção do status hídrico. De modo semelhante, Lee et al. (2008) mostraram que a osmorregulação em Trifolium repens L. ocorre pela degradação do amido de reserva e não pela síntese de novo dos carboidratos solúveis.

O amido é o principal carboidrato de reserva dos rizomas de Costus arabicus (Santos 2009). No presente trabalho, verificou-se que, em geral, a concentração deste polissacarídeo foi mais elevada nos rizomas das plantas submetidas à suspensão de rega, embora, não tenham sido verificadas diferenças estatisticamente significativas. A diminuição no conteúdo de amido nos rizomas associada ao maior crescimento das plantas irrigadas diariamente (dados não mostrados) sugere que esse polissacarídeo foi utilizado como fonte de energia para o crescimento das plantas. Carvalho \& Dietrich (1993) também observaram uma diminuição no conteúdo de frutanos armazenados nos órgãos subterrâneos (rizóforos) de Vernonia herbacea (Vell.) Rusby, uma espécie do Cerrado, na fase de brotação e crescimento ativo. Em contrapartida, a manutenção dos teores de amido nos rizomas das plantas dos tratamentos $7 \mathrm{~d}$ e $15 \mathrm{~d}$ sugere a ocorrência de dormência do órgão subterrâneo possivelmente em resposta ao déficit hídrico imposto.
Esse comportamento indica uma estratégia de evitação à seca, plausível de ocorrência em plantas de ambientes úmidos, como Costus arabicus. No entanto, estudos adicionais considerando as relações fonte-dreno, regulação da via de síntese de amido e sacarose, e sinalização hormonal, com ênfase no ácido abscísico, poderão colaborar significativamente para o entendimento das respostas observadas e confirmação de um mecanismo de evitação à seca nessas plantas.

Aspectos anatômicos e ultra-estruturais dos rizomas Segundo Solereder e Meyer (1930 apud Tomlinson 1956), o rizoma das espécies das subfamílias Costoideae e Zingiberoideae nem sempre apresenta periderme. As camadas superficiais do rizoma de Costaceae são comumente suberizadas, e essa suberização às vezes ocorre apenas após a formação da periderme (Tomlinson 1969). Em Costus spiralis (Jacquin) Roscoe, Oliveira et al. (1986) observaram que o rizoma é protegido por um conjunto de células suberosas, diferentemente do rizoma de Costus pilgeri K. Schum., que apresenta periderme precocemente desenvolvida e felogênio pouco diferenciado (Lorca et al. 1995). Em Costus arabicus, o rizoma é revestido pela epiderme, como em Costus igneus (Pazhanichamy et al. 2010), ou pelo súber estratificado.

Espécies da família Heliconiaceae, como por exemplo, Heliconia angusta Vell. e $H$. velloziana L. Emygd. (Simão \& Scatena 2001) apresentam organização anatômica do rizoma semelhante ao de Costus arabicus, ou seja, com delimitação entre córtex e cilindro vascular. Em Canna indica L. (Cannaceae), a presença da endoderme no rizoma foi inicialmente observada por Van Fleet (1942); e um estudo com Canna edulis Kerr-Gawler constatou que no rizoma dessa espécie, a endoderme com estrias de Caspary delimita o córtex do cilindro vascular (Alonso \& Moraes-Dallaqua 2004), característica também observada em Costus arabicus. Menezes et al. (2005) também constataram a presença da endoderme no rizoma de Zingiber officinale Roscoe (Zingiberaceae).

O rizoma das espécies das subfamílias Costoideae e Zingiberoideae apresenta tecido vascular interno à endoderme e parênquima com inúmeros grãos de amido (Tomlinson 1956). Em Costus spiralis, Oliveira et al. (1986) constataram que o rizoma apresenta tais características anatômicas, além de idioblastos providos de conteúdo amorfo amarelado, algumas vezes de aspecto granuloso. No córtex, também foi observada a presença de cristais prismáticos e 

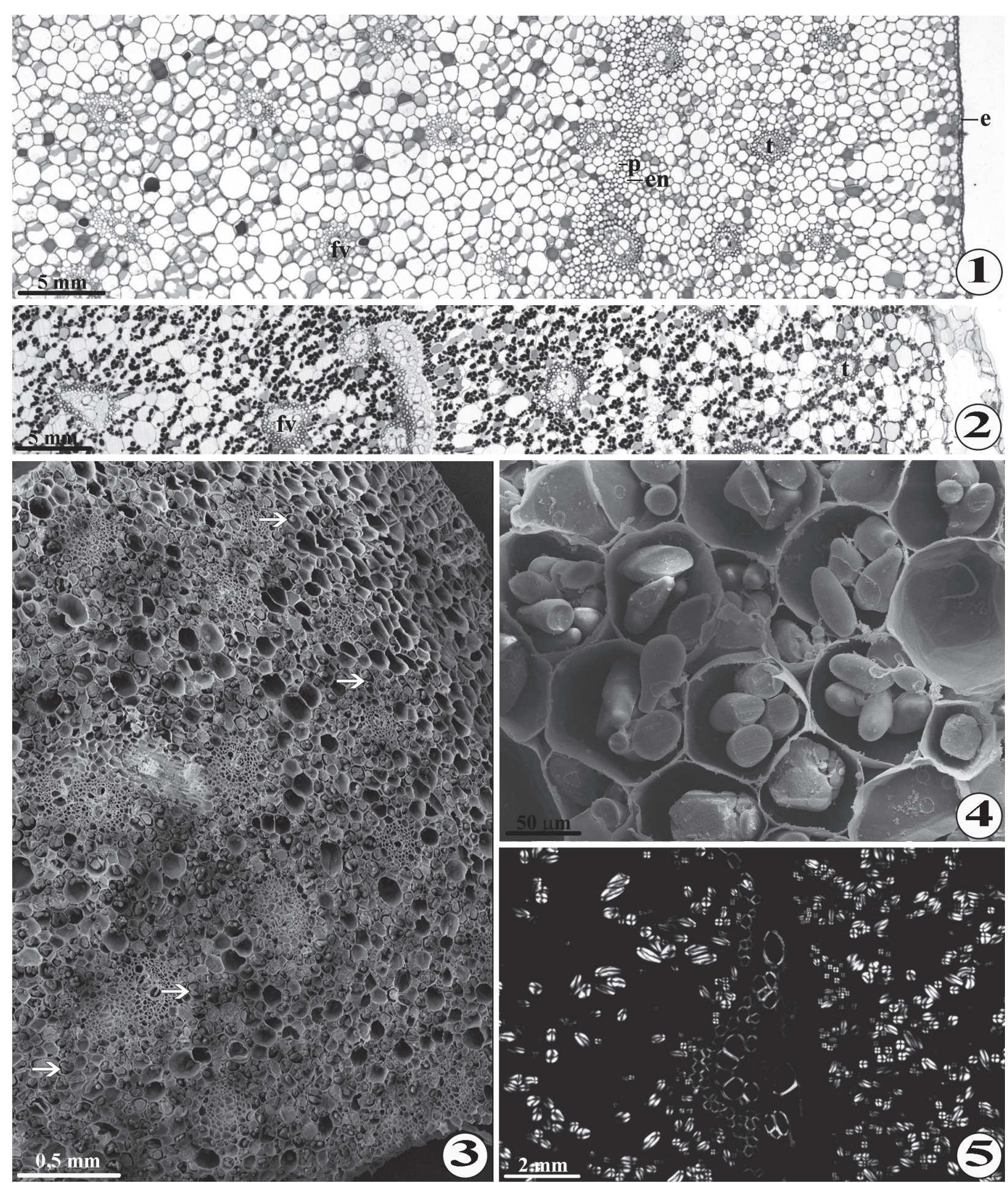

Figura 3. Secções transversais em microscopia de luz (1, 2 e 5) e em microscopia eletrônica de varredura (3 e 4) do rizoma de plantas de Costus arabicus L. irrigadas a cada sete dias (7d). 1. Secção corada com azul de toluidina mostrando a estrutura anatômica do rizoma. 2. Grãos de amido do córtex e do cilindro vascular corados com lugol. 3. Aspecto geral do rizoma, mostrando os grãos de amido (setas). 4. Detalhe dos grãos de amido. 5. Grãos de amido sob luz polarizada. e: epiderme; en: endoderme; fv: feixe vascular; p: periciclo; t: traço foliar.

Figure 3. Light microscopy (1,2 and 5) and scanning electron microscopy (3 and 4) of transversal sections of rhizomes of plants of Costus arabicus L. irrigated every seven days (7d). 1. Section stained with toluidine blue, showing the anatomical structure of the rhizome. 2. Starch grains in the cortex and vascular cylinder stained with lugol. 3. General aspect of the rhizome showing starch grains (arrows). 4. Detail of starch grains. 5. Starch grains under polarized light. e: epidermis; en: endodermis; fv: vascular bundle; p: pericycle; s: suber; t: leaf trace. 
endoderme típica com células com espessamento em U (Oliveira et al. 1986) ou com estrias de Caspary (Silva 2009). Lorca et al. (1995) observaram uma grande área cortical no rizoma de Costus pilgeri e, nessa região, foram visualizados cristais (drusas) e inúmeros grãos de amido, exceto na última camada (endoderme). A presença de cristais prismáticos também foi observada em Costus spiralis e C. arabicus, e de material amorfo pardo-amarelado em idioblastos no rizoma de Costus spiralis, Costus arabicus e Hedychium coronarium Koening (Jorge et al. 1998). Dados obtidos no presente trabalho corroboram parte das descrições acima, tais como a delimitação entre o córtex e o cilindro vascular e a presença de idioblastos, parênquima amilífero, cristais e endoderme desprovida de amido com estrias de Caspary.

Segundo Menezes et al. (2005), o periciclo do caule de Zingiber officinale é, sem dúvida, a camada de geração de tecidos vasculares. Diferentemente de Heliconia angusta, Heliconia velloziana (Simão \& Scatena 2001),e Costus pilgeri (Lorca et al. 1995), que apresentam periciclo unisseriado, e Canna edulis que possui periciclo plurisseriado (Alonso \& Moraes-Dallaqua 2004), Costus arabicus apresenta periciclo bisseriado, sendo a camada responsável pela formação dos feixes vasculares. Em um estudo recente, Silva (2009) observou que o periciclo do rizoma de Costus spiralis ao gerar novos feixes, produzia, junto a esse tecido, células que se tornavam fibras. Dessa forma, os feixes gerados pelo periciclo eram envoltos total ou parcialmente pelas fibras produzidas por esse tecido. Em contrapartida, as fibras que envolveram os traços foliares eram geradas pelo procâmbio. Em Costus arabicus, verificou-se que as fibras formam uma bainha que envolve completamente o feixe vascular.

Assim como verificado no presente trabalho, Heliconia angusta e $H$. velloziana também possuem feixes vasculares colaterais (Simão \& Scatena 2001). Em Costus afer Ker Gawl. e C. lucanusianus J. Braun \& K. Schum., Edeoga \& Okoli (1997) observaram algumas diferenças anatômicas nos rizomas com relação ao tamanho dos vasos de xilema e ao número de camadas de esclerênquima ao redor do feixe vascular. Enquanto Costus afer possui apenas uma camada de esclerênquima ao redor dos feixes e pequenos vasos de xilema, Costus lucanusianus possui de 2-3 camadas e os vasos de xilema são grandes. Lorca et al. (1995) verificaram que os feixes vasculares colaterais do córtex e do cilindro central do rizoma de Costus pilgeri possuem bainha de fibras pouco lignificadas em seu entorno. Em Costus arabicus, os feixes vasculares estão envoltos por 1-3 camadas de bainha esclerenquimática.

Alterações na estrutura do rizoma somente foram observadas nas plantas de Costus arabicus irrigadas a cada 15 dias, cujas células do tecido de revestimento e das camadas corticais mais externas tenderam ao colapso, apesar de não haver diferença significativa do potencial osmótico da seiva do rizoma e do CRA entre as plantas $7 \mathrm{~d}$ e $15 \mathrm{~d}$, mas com diferenças significativas do potencial hídrico foliar. Segundo Huang \& Fry (1998), a contração das células corticais das raízes de Festuca arundinacea Schreb. (Poaceae) é uma consequênca da diminuição do seu potencial hídrico e da pressão de turgor. Em Setaria anceps Stapf ex Massey e Paspalum pamiculatum L., Melo et al. (2007) observaram que a diminuição da espessura do córtex radicular está relacionada com a diminuição do potencial hídrico e poderia favorecer maior prevenção de perda de água da planta para o solo.

Análises ao microscópio eletrônico de varredura dos grãos de amido de órgãos subterrâneos tuberosos evidenciaram diferentes formas, tais como: Curcuma sp. (Zingiberaceae) possui grãos arredondados e ovais; Typhonium sp. (Araceae) apresenta grãos arredondados e poligonais; e Vigna vexillata (L.) A. Rich. (Fabaceae) possui grãos cupuliformes, convexos e biconvexos (Vimala \& Nambisan 2005). Embora o formato dos grãos de amido encontrados nos rizomas pareça ser constante e característico para determinados gêneros, entre eles Costus (Tomlinson 1956), algumas diferenças foram documentadas para as espécies desse gênero. Segundo Lorca et al. (1995), C. pilgeri possui grãos simples, heteromórficos, geralmente ovais. Em C. afer, os grãos de amido apresentaram formatos achatado, oval, circular e irregular, enquanto em C. lucanusianus, os mesmo foram visualizados apenas nas formas achatada e oval (Edeoga \& Okoli 1997). Contudo, essas análises não foram realizadas sob microscopia eletrônica de varredura, como no presente trabalho, que mostrou realmente o formato do grão de amido, visto que em secções transversais visualizadas em microscopia de luz, os grãos de amido podem não estar íntegros. As análises das eletromicrografias mostraram que os grãos de amido das plantas de Costus arabicus irrigadas diariamente e daquelas submetidas ao déficit hídrico possuem os mesmos formatos.

Tomlinson (1956) relatou que é muito frequente a presença de compostos fenólicos em todas as espécies de Zingiberaceae e que esses aparecem comumente 


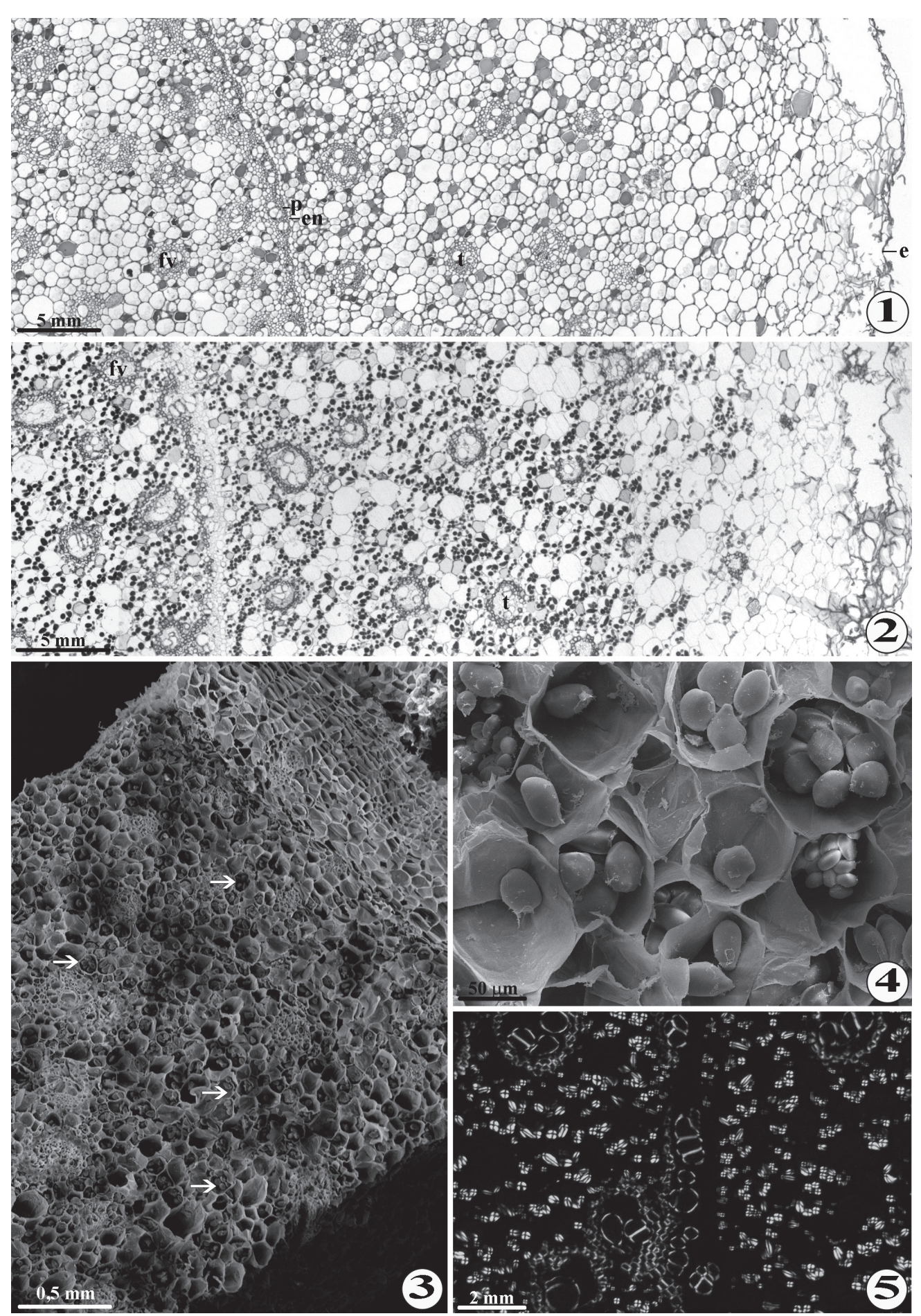

Figura 4. Secções transversais em microscopia de luz (1, 2 e 5) e em microscopia eletrônica de varredura (3 e 4) do rizoma de plantas de Costus arabicus L. irrigadas a cada 15 dias (15d). 1. Secção corada com azul de toluidina mostrando a estrutura anatômica do rizoma. 2. Grãos de amido do córtex e do cilindro vascular corados com lugol. Observe a ausência dos grãos de amido nas camadas subepidérmicas. 3. Aspecto geral do rizoma, mostrando os grãos de amido (setas). 4. Detalhe dos grãos de amido. 5. Grãos de amido sob luz polarizada. e: epiderme; en: endoderme; fv: feixe vascular; p: periciclo; t: traço foliar.

Figure 4. Optical microscopy (1,2 and 5) and scanning electron microscopy (3 and 4) of transversal sections of rhizomes of plants of Costus arabicus L. irrigated every 15 days (15d). 1. Section stained with toluidine blue, showing the anatomical structure of the rhizome. 2. Starch grains in the cortex and vascular cylinder stained with lugol. Note the absence of starch grains in the subepidermal layers. 3. General aspect of the rhizome showing starch grains (arrows). 4. Detail of starch grains. 5. Starch grains under polarized light. e: epidermis; en: endodermis; fv: vascular bundle; p: pericycle; s: suber; t: leaf trace. 
associados aos feixes vasculares ou adjacentes ao parênquima da bainha. No presente estudo, idioblastos com conteúdo fenólico foram observados tanto associados aos feixes vasculares quanto dispersos no córtex e no cilindro vascular. Várias funções essenciais têm sido atribuídas a diferentes classes de compostos fenólicos. Os fenóis proporcionam defesa contra patógenos e possuem notável atividade antimicrobiana, e os taninos, impedem a herbivoria (Castro \& Demarco 2008).

Tomlinson (1969) descreveu o rizoma e a raiz das espécies de Costaceae como sendo iguais aos da família Zingiberaceae, com apenas uma diferença: ausência de células secretoras de óleo em Costaceae. O teste com Sudan IV foi negativo para a presença de substâncias lipofílicas nos rizomas de Costus arabicus, confirmando a diferença existente entre os representantes dessas duas famílias.

Neste trabalho verificou-se que o déficit hídrico imposto foi suficiente para gerar mudanças fisiológicas, bioquímicas e anatômicas nas plantas de Costus arabicus L. Essas alterações sugerem a ocorrência de um mecanismo de evitação à seca, e demonstram que as alterações anatômicas foram dependentes da intensidade e duração do déficit hídrico.

\section{Agradecimentos}

Os autores agradecem à FAPESP pelos auxílios financeiros (2005/04139-7 e 2009/01570-0), ao $\mathrm{CNPq}$ pela bolsa de mestrado concedida à V.P. Costa (564572/2008-0) e pela bolsa de Produtividade Científica a M.A.M. Carvalho, ao NAP/MEPA (ESALQ/USP) pela utilização do MEV, à Dra. Lúcia Rossi (Instituto de Botânica) pela identificação do material botânico e à Profa. Dra. Beatriz Appezzato-da-Glória e Marli K.M. Soares (ESALQ/ USP), pela utilização do microscópio Leica.

\section{Literatura citada}

Alonso, A.A. \& Moraes-Dallaqua, M.A. 2004. Morfoanatomia do sistema caulinar de Canna edulis Kerr-Gawler (Cannaceae). Revista Brasileira de Botânica 27: 229-239.

Amaral, L.I.V., Costa, P.M.F., Aidar, M.P.M., Gaspar, M. \& Buckeridge, M.S. 2007. Novo método enzimático rápido e sensível de extração e dosagem de amido em materiais vegetais. Hoehnea 34: 425-431.

Asseng, S., Ritchie, J.T., Smucker, A.J.M. \& Robertson, M.J. 1998. Root growth and water uptake during water deficitand recovering in wheat. Plantand Soil 201:265-273.
Basu, P.S., Berger, J.D., Turner, N.C., Chaturvedi, S.K., Ali, M. \& Siddique, K.H.M. 2007. Osmotic adjustment of chickpea (Cicer arietinum) is not associated with changes in carbohydrate composition or leaf gas exchange under drought. Annals of Applied Biology 150: 217-225.

Berlyn, G.P. \& Miksche, J.P. 1976. Botanical microtechnique and cytochemistry. Iowa State University Press, Ames.

Bohnert, H.J. \& Jensen, R.G. 1996. Strategies for engineering water stress tolerance in plants. Trends in Biotechnology 14: 89-97.

Bray, E.A. 1993. Molecular responses to water deficits. Plant Physiology 103: 1035-1040.

Buckeridge, M.S., Tiné, M.A.S., Santos, H.P. \& Lima, D.U. 2000. Polissacarídeos de reserva de parede celular em sementes: estrutura, metabolismo, funções e aspectos ecológicos. Revista Brasileira de Fisiologia Vegetal 12: 137-162.

Carvalho, M.A.M. \& Dietrich, S.M.C. 1993. Variation in fructan content in the underground organs of Vernonia herbacea (Vell.) Rusby at different phenological phases. New Phytologist 123: 735-740.

Carvalho, M.A.M., Pinto, M.M. \& Figueiredo-Ribeiro, R.C.L. 1998. Inulin production by Vernonia herbacea as influenced by mineral fertilization and time of harvest. Revista Brasileira de Botânica 21: 275-280.

Castro, C.E.F. 1995. Inter-relações das famílias das Zingiberales. Revista Brasileira de Horticultura Ornamental 1: 2-11.

Castro, M.M. \& Demarco, D. 2008. Phenolic compounds produced by secretory structures in plants: a brief review. Natural Product Communications 8: 1273-1284.

Chaves, M.M., Pereira, J.S., Maroco, J., Rodrigues, M.L., Ricardo, C.P.P., Osorio, M.L., Carvalho, I., Faria, T. \& Pinheiro, C. 2002. How plants cope with water stress in the field? Photosynthesis and Growth. Annals of Botany 89: 907-916.

Clark, R.B. 1975. Characterization of phosphatase of intact maize roots. Journal of Agriculture and Food Chemistry 23: 458-460.

Davies, W.J. \& Zhang, J. 1991. Root signals and the regulation of growth and development of plants in drying soil. Annual Review of Plant Physiology and Plant Molecular Biology 42: 55-76.

Dubois, M., Gilles, K.A., Hamilton, J.K., Rebers, P.A. \& Smith F. 1956. Colorimetric method for determination of sugars and related substances. Analytical Chemistry 28: 350-356.

Edeoga, H.O. \& Okoli, B.E. 1997. Anatomy and systematics in the Costus afer $-C$. lucanusianus complex (Costaceae). Acta Phytotaxonomica et Geobotanica 48: 151-158. 
Fan, L. \& Neumann, P.M. 2004. The spatially variable inhibition by water deficit of maize root growth correlates with altered profiles of proton flux and cell wall pH. Plant Physiology 135: 2291-2300.

Fan, L., Linker, R., Gepstein, S., Tanimoto, E., Yamamoto, R. \& Neumann, P.M. 2006. Progressive inhibition by water deficit of cell wall extensibility and growth along the elongation zone of maize roots is related to increase lignin metabolism and progressive stellar accumulation of wall phenolics. Plant Physiology 140: 603-612.

Geigenberger, P., Reimholz, R., Geiger, M., Merlo, L., Canale, V. \& Stitt, M. 1997. Regulation of sucrose and starch metabolism in potato tubers in response to short-term water deficit. Planta 201: 502-518.

Horridge, G.A. \& Tamm, S.L. 1969. Critical point drying for scanning electron microscopy study of ciliary motion. Science 163: 817-818.

Huang, B. \& Fry, J.D. 1998. Root anatomical, physiological and morphological responses to drought stress for tall fescue cultivars. Crop Science 38: 1017-1222.

Jensen, W.A. 1962. Botanical histochemistry: principles and practice. W.H. Freeman, San Francisco.

Johansen, D.A. 1940. Plant microtechnique. McGraw-Hill, New York.

Jones, H.G. \& Corlett, J.E. 1992. Current topics in drought physiology. Journal of Agricultural Science 119: 291-296.

Jorge, L.I.F., Gonzalez, E., Silva, M.L.P. \& Vicente, R. 1998. Exame microscópico-comparativo das espécies popularmente designadas "cana-do-brejo". Revista de Ciências Farmacêuticas 19: 39-47.

Judd, W.S., Campbell, C.S., Kellogg, E.A., Stevens, P.F. \& Donoghue, M.J. 2009. Sistemática vegetal: um enfoque filogenético. 3 ed. Artmed, Porto Alegre.

Karnovsky, M.J. 1965. A formaldehyde-glutaraldehyde fixative of high osmolality for use in electron microscopy. Journal of Cell Biology 27: 137-138.

Lee, B-R., Jin, Y-L., Jung, W-J., Avice, J-C., MorvanBertrand, A., Ourry, A., Park, C-W. \& Kim, T-H. 2008. Water-deficit accumulates sugars by starch degradation not by de novo synthesis in white clover leaves (Trifolium repens). Physiologia Plantarum 134: 403-411.

Lorca, G.L., Amat, A.G., Yajia, M.E. \& Gonzalez, C.F. 1995. Caracteres microscópicos del rizoma de Costus pilgeri K. Schum. (Zingiberaceae), utilizado como agente antihipertensivo y abortivo em la medicina popular de Misiones (Argentina). Acta Farmaceutica Bonaerense 14: 17-20.

Lorenzi, H. \& Souza, H.M. 1999. Plantas ornamentais do Brasil: arbustivas, herbáceas e trepadeiras. 2 ed. Instituto Plantarum, Nova Odessa.
McIlvaine, T.C. 1921. A buffer solution for colorimetric comparison. Journal of Biological Chemistry 49: 183-186.

Melo, H.C., Castro, E.M., Soares, A.M., Melo, L.A. \& Alves, J.D. 2007. Alterações anatômicas e fisiológicas em Setaria anceps Stapf ex Massey e Paspalum paniculatum L. sob condições de déficit hídrico. Hoehnea 34: 145-153.

Menezes, N.L., Silva, D.C., Arruda, R.C.O., Melo-dePinna, G.F., Cardoso, V.A., Castro, N.M., Scatena, V.L. \& Scremin-Dias, E. 2005. Meristematic activity of the endodermis and the pericycle in the primary thickening in monocotyledons. Considerations on the "PTM". Anais da Academia Brasileira de Ciências 77: 259-274.

Morillon, R. \& Lassalles, J-P. 2002. Water deficits during root development: effects on the growth of roots and the osmotic water permeability of isolated root protoplasts. Planta 214: 392-399.

Oliveira, C.C., Cabrini, D.A., Santos, E.P., Marques, M.C.A. \& Buchi, D.F. 2008. Canova medication and medicinal plants in south of Brazil. In: R. Pretorius (ed.).Trends and developments in ethnopharmacolgy. Research Signpost, Kerala.

Oliveira, F., Saito, M.L. \& Chunzum, M. 1986. Caracterização morfológica da cana-do-brejo. Revista Brasileira de Farmacognosia 1: 123-135.

Oparka, K.J. \& Wright, K.M. 1988. Osmotic regulation of starch synthesis in potato tubers. Planta 174: 123-126.

Oparka, K.J. \& Wright, K.M. 1988. Influence of cell turgor on sucrose partitioning in potato tuber storage tissues. Planta 175: 520-526.

Pastorini, L.H., Bacarin, M.A., Trevizol, F.C., Bevald, C.M.P. \& Fernandes, H.S. 2003. Produção e teor de carboidratos não estruturais em tubérculos de batata obtidos em duas épocas de plantio. Horticultura Brasileira 21: 660-665.

Pazhanichamy, K., Pavithra, S., Rubini, S., Lavanya, B., Ramya, I. \& Eevera, T. 2010. Morphological, anatomical and proximate analysis of leaf, root, rhizome of Costus igneus. Journal of Pharmacy Research 3: 747-752.

Pelleschi, S., Rocher, J.P. \& Prioul, J.L. 1997. Effect of water restriction on carbohydrate metabolism and photosynthesis on mature maize leaves. Plant, Cell and Environment 20: 493-503.

Piro, G., Leucci, M.R., Waldron, K. \& Dalessandro, G. 2003. Exposure to water stress causes changes in the biosynthesis of cell wall polysaccharides in roots of wheat cultivars varying in drought tolerance. Plant Science 165: 559-569.

Sakai, W.S. 1973. Simple method for differential staining of paraffin embedded plant material using toluidine blue O. Stain Technology 48: 247-249. 
Santisopasri, V., Kurotjanawong, K., Chotineeranat, S., Piyachomkwan, K., Sriroth, K. \& Oates, C.G. 2001. Impact of water stress on yield and quality of cassava starch. Industrial Crops and Products 13: 115-129.

Santos, V.R. 2009. Crescimento, propagação, floração e compostos de reserva em Costus arabicus L. Tese de Doutorado, Universidade Estadual de Campinas, Campinas.

Sharp, R.E. \& Lenoble, M.E. 2002. ABA, ethylene and the control of shoot and root growth under water stress. Journal of Experimental Botany 53: 33-37.

Sharp, R.E., Poroyko V., Hejlek, L.G., Spolle, W.G., Springer, G.K., Bohnert, H.J. \& Nguyen H.T. 2004. Root growth maintenance during water deficits: physiology to functional genomics. Journal of Experimental Botany 55: 2343-2351.

Shinozaki, K. \& Yamaguchi-Shinozaki, K. 1997. Gene expression and signal transduction in water stress response. Plant Physiology 115: 327-334.

Silva, C.G. 2009. O espessamento primário no sistema caulinar e a continuidade entre esses tecidos nos órgãos vegetativos de Zingiberaceae e Costaceae: enfoque nos tecidos endoderme e periciclo. Dissertação de Mestrado, Universidade de São Paulo, São Paulo.

Simão, D.G. \& Scatena, V.L. 2001. Morphology and anatomy in Heliconia angusta Vell. and H. velloziana L. Emygd. (Zingiberales: Heliconiaceae) from the Atlantic forest of southeastern Brazil. Revista Brasileira de Botânica 24: 415-424.

Somogyi, M. 1945. A new reagent for the determination of sugars. Journal of Biological Chemistry 160: 61-63.

Tomlinson, P.B. 1956. Studies in the systematic anatomy of Zingiberaceae. Journal of the Linnean Society 55: 547-592.
Tomlinson, P.B. 1969. Commelinales-Zingiberales. In: P.B. Tomlinson (ed.). Anatomy of the monocotyledons. Oxford University Press, Oxford, v. 3, p. 295-324.

Turner, N.C. 1986. Adaptation to water deficits: a changing perspective. Australian Journal of Plant Physiology 13: 175-190.

Van Fleet, D.S. 1942. The developmental and distribution of the endodermis and an associated oxidase system in monocotyledonous plants. American Journal of Botany 29: 1-15.

Vimala, B. \& Nambisan, B. 2005. Tropical minor tubers crops. Central Tuber Crops Research Institute, Trivandrum.

Weatherley, P.E. 1950. Studies in the water relations of cotton plant. I. The field measurement of water deficits in leaves. New Phytologist 49: 81-97

Whittaker, A., Martinelli, T., Farrant, J.M., Bochicchio, A. \& Vazzana, C. 2007. Sucrose phosphate synthase activity and the co-ordination of carbon partitioning during sucrose and amino acid accumulation in desiccation-tolerant leaf material of the $\mathrm{C}_{4}$ resurrection plant Sporobolus stapfianus during dehydration. Journal of Experimental Botany 58: 3775-3787.

Zhang, T., Wang, Z., Yin, Y., Cai, R., Yan, S. \& Li, W. 2010. Starch content and granule size distribution in grains of wheat in relation to post-anthesis water deficits. Journal of Agronomy \& Crop Science 196: 1-8.

Zobayed, S.M.A., Afreen, F., \& Kozai, T. 2007. Phytochemical and physiological changes in the leaves of St John's wort plants under a water stress condition. Environmental and Experimental Botany 59: 109-116. 